\title{
El fenómeno Booktube, entre el fandom y la crítica literaria'
}

\author{
Booktube Phenomenon, between Fandom and Literary Criticism
}

\author{
MARIO DE LA TORRE-ESPINOSA \\ Universidad de Granada \\ España \\ mariodelatorre@ugr.es
}

(Recibido: 29/II/2OI8; aceptado: o6/o5/2019)

Resumen. El fenómeno Booktube se configura en un claro ejemplo de la cultura participativa, donde los usuarios toman las riendas de los medios para aportar sus propias ideas, en este caso referidas a la literatura. En este trabajo se analiza el carácter que toman las producciones audiovisuales de los booktubers, intentando dilucidar si se trata de un fenómeno fandom que además puede ser evaluado como crítica literaria. Tras revisar algunas ideas en torno a la crítica, estaríamos dentro de la categoría en la que EdwardW. Said incluye a las reseñas de libros $o$ al periodismo literario, aunque teniendo en cuenta su carácter amateur. También se resalta el que se opte por formas de literatura que no forman parte del canon central del sistema cultural, lo que dota de una gran originalidad a la selección de los títulos propuestos. Dada la impronta entre el público juvenil, se recomienda emprender estudios que aborden la eficacia de este tipo de prácticas en la promoción de la lectura, especialmente en el ámbito universitario.

Palabras clave: Booktube; crítica literaria; redes sociales; participación cultural; promoción de la lectura.
Abstract. The booktube phenomenon is configured as a clear example of participatory culture, where users take control of media offering their own ideas, in this case referred to literature. This article discusses the character of audiovisual productions created by booktubers. Additionally, it tries to resolve if these cases are a fandom phenomenon that also can be considered as literary criticism. After reviewing some ideas towards the criticism, these videos are found to be in the category established by Edward W. Said composed by reviews and literary journalism, although taking into account their amateur nature. Also, it is remarked that the booktubers selection of literary forms do not take part in the central canon of the cultural system. This situation provides the selection of the titles with a great originality. Because of the importance of Booktube among the young audience of readers, new research is recommended in this area for reading promotion, especially at the university level.

Keywords: Booktube; literary criticism; social media; cultural participation; reading promotion.

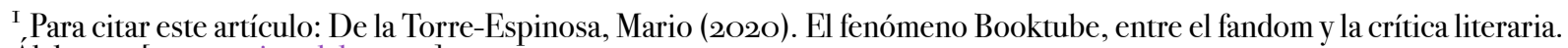
Álabe 2I . [www.revistaalabe.com]

DOI: IO.I5645/Alabe2020.2I.6
} 


\section{Introducción}

La diversidad de medios presente en el ecosistema mediático actual ha conllevado un cambio en gran parte de las formas de comunicación, entre ellas la literaria. Dentro de esta lógica, esta diversificación ha impulsado un nuevo paradigma comunicativo capaz de alterar lo que tradicionalmente se había venido imponiendo sobre fenómenos como la lectura o la escritura, propiciando así el surgimiento a su vez de nuevas formas de literariedad.

Para comenzar, asumimos que la lectura ya no es ni unimedial ni unimodal. La convergencia de medios actual, siguiendo los presupuestos teóricos de Henry Jenkins (2008), ha conllevado una expansión de los contenidos a través de medios y plataformas, contribuyendo de esta forma al fomento de la participación activa por parte de los usuarios, que en la cultura digital han pasado a ocupar una posición central en el sistema literario. Si realizamos una lectura desde la Teoría de los Polisistemas de Itamar Even-Zohar (I999), podemos decir que el polisistema literario ha sufrido una traslación en su interior, puesto que los consumidores han pasado de ser agentes pasivos (aunque con capacidad de decisión a través de sus gustos literarios) a constituirse también en productores. Estaríamos hablando de la conversión de la ciudadanía en lo que se denominó prosumer (consumidor-productor) en los setenta, ya sea desde un posicionamiento economicista y aliado del capitalismo como lo enunciara por primera vez Alvin Toffler (I994), o bien desde el posicionamiento de Jean Cloutier y su concepto de emirec (I973), donde estas relaciones debían efectuarse desde la horizontalidad (Aparici y García-Marín, 20I8). O, si queremos también, con George Landow (1997), que denominaría en el ámbito literario a este fenómeno como el de los wreaders, neologismo surgido de la combinación de writers y readers para designar a una nueva generación que se implicaría de lleno en los procesos de producción y consumo de lo literario.

Pero más allá de esta significativa hibridación, lo más interesante, y menos estudiado, es cómo estos nuevos usuarios lectores/consumidores, además de confundirse con los productores/autores, también se están configurando en parte del factor institución, en concreto cambiando cuestiones inherentes a la crítica tradicional, como puede ser el haber propiciado el paso desde un posicionamiento fuertemente jerarquizado a otro basado en la horizontalidad.

Para Frank Kermode (I999), la institución estaría formada por aquellos elementos del sistema cultural de un país que aseguran tanto el uso como la continuidad en la presencia en el repertorio de un conjunto de obras. Dicha selección se ha venido realizando tradicionalmente de acuerdo a los criterios establecidos por una determinada comunidad académica u otra institución similar que ostente una posición de superioridad intelectual frente al resto. Este ancestral ejercicio de autoridad a la hora de dirimir los gustos de la población, aunque aún vigente en gran medida, ha ido perdiendo valor en la cultura digital en cuanto se han ido imponiendo nuevas formas que retan el comportamiento tradicional a la hora de sancionar, o no, la lectura de determinadas obras. 
Este fenómeno aplicado sobre el ámbito literario tiene un hito clave en el desarrollo de la cibercultura, definida por Domingo Sánchez-Mesa como "el fruto de la confluencia de la aplicación cotidiana de los procesadores electrónicos a multitud de actividades humanas y de la apertura e internacionalización de espacios virtuales de trabajo, ocio, educación, comercio, creación artística, información, de comunicación en suma" (2004: I4). Tan importante es su impronta, que la interferencia de ámbitos, el virtual y el real, se produce sin interrupción alguna, generándose un espacio pleno de heterodoxia en sus formas, incluidas las literarias.

Esta tendencia se ha extendido al ámbito de la crítica literaria, al invitar al lector a adoptar una posición activa a la hora de ejercer y compartir su juicio sobre ciertas obras (ya sea mediante comentarios en blogs especializados o, simplemente, mediante la valoración de la compra efectuada de títulos literarios en Amazon, por ejemplo). Las lecturas, y los comentarios acerca de las mismas, sean estos de la índole que sean, son ahora compartidas en diferentes plataformas de internet, ya sea en forma de tuit, de entrada de blog o de comentario de Facebook, y además lanzándose de forma abierta en redes. El ciberespacio se configura así como espacio para el encuentro y el intercambio de ideas sobre la presunta calidad de las obras literarias, en muchos casos a modo de tertulias, pero ahora en un nuevo contexto virtual.

\section{El fenómeno Booktube}

Una clara muestra de esta corriente la hallamos en el fenómeno Booktube, compuesto por youtubers que usan las posibilidades comunicativas y estéticas de la red social YouTube para crear canales dedicados a la literatura, y cuya comunidad de seguidores está compuesta en su gran mayoría por jóvenes. Tanto es así que la presencia de estos “críticos" o "entertainers" en redes ha sido advertida por la industria editorial, usándolos para la promoción de las novedades de sus catálogos editoriales ${ }^{2}$. Y todo porque el número de seguidores que tienen algunas cuentas ha convertido a sus propietarios en influencers o, siguiendo la terminología polisistémica, en integrantes de la institución.

Podríamos definir este tipo de prácticas audiovisuales basadas en la oralidad, desde punto de vista narratológico y siguiendo a Genette, como una práctica paratextual, en concreto un caso de epitextualidad, ya que no estaría "anexado al texto en su mismo volumen, sino que circula libremente en un espacio físico y social prácticamente ilimitado" (200I: 346). El investigador francés no auguraba que este tipo de espacio también podría ser virtual, e ignoraba las ventajas que iban a proporcionar fenómenos como booktube, los booktrailers o los foros de lectores, ya que tienen un bajo coste, permiten dirigirse di-

\footnotetext{
${ }^{2}$ Para el análisis de este trabajo, se ha tomado como referencia principal el canal de YouTube de Sebastián García Mouret, titulado El coleccionista de mundos (https://www.youtube.com/channel/UCcCdTv9Vumo66-3roW/3RvrQ), y el de Javier Ruescas (https:/ / www.youtube.com/user/ruescasj), por constituirse en dos ejemplos paradigmáticos para el ámbito hispánico de lo expresado en el presente artículo.
} 
rectamente al lector con unos contenidos muy actualizados, y establecen una interacción inmediata con los usuarios para conocer sus necesidades reales (Lluch, Tabernero-Sala y Calvo-Valios, 20I5: 802).

Las propuestas de Booktube son muy simples, siguiendo la estética youtuber iniciada en 2007 con Justine Ezarik, donde contamos con la presencia de "un usuario de internet, por lo general joven, que sube videos a la plataforma de manera regular, cuenta con un número elevado de suscriptores y además consigue ganar dinero por publicar videos" (Márquez y Ardévol, 20I2: 35), y donde habla a su vez a una audiencia joven a la que interpela y que entiende lo que les es contado de una manera totalmente naturalizada. Son videos de corta duración, donde el booktuber presenta su espacio con un discurso que incluye un narratario explícito, que somos los propios usuarios. La forma de enunciación recurre así, para dirigirse a nosotros, a fórmulas como "por fin aquí tenéis", "como os dije", "como os prometí" ... haciendo al usuario de su canal partícipe de las experiencias lectoras narradas, y conminándoles a aportar sus ideas en los comentarios al video en YouTube.

Esta interpelación directa al espectador/lector tiene una funcionalidad esencial, ya que el carácter prescriptivo de los comentarios emanados del canal debe lograr la máxima eficacia persuasiva posible. De ahí que la mirada de los booktubers se dirija a cámara, apelando directamente al usuario, convirtiendo la propuesta, en términos de gramática audiovisual, en una suerte de plano subjetivo. No es baladí tampoco que la escala del plano sea medio corto, puesto que la focalización narrativa hace que la ocularización y la auricularización (Gaudreault y Jost, 2OOI), es decir, lo que vemos y oímos, coincida con el punto de vista del espectador en el caso de que estuviera justo delante del booktuber, sugiriendo de esta forma una gran proximidad e intimidad con él. Esto, desde el punto de vista de la psicología de la percepción, propicia un gran efecto persuasivo sobre el receptor del mensaje audiovisual, haciendo que su contenido cale con una mayor intensidad.

Esto no sería algo banal si tenemos en cuenta que lo que desde este trabajo pretendemos indagar es acerca de la posibilidad de considerar al fenómeno Booktube como crítica literaria. Para ello, primero debemos tener en cuenta que este es un concepto en constante evolución, desde el abandono de las cuestiones filológicas en el siglo XVIII por el ejercicio de interpretaciones desde el pensamiento racional, a la llegada en el siglo XX de una politización cada vez mayor en este ámbito (Alberro, 2OII), asociándose a los diferentes tipos de poder, como se pudo observar en los debates en torno al canon literario en los noventa (Sullá, I998) y propiciando el desarrollo de los Estudios Culturales.

Así es como lo entiende Edward W. Said, para quien, en torno a la profesión del crítico literario, dice que "los textos tienen modos de existencia que hasta en sus formas más sublimadas están siempre enredados con la circunstancia, el tiempo, el lugar y la sociedad; dicho brevemente, están en el mundo y de ahí que sean mundanos" (2004: 54). Y es que el crítico literario tiene un carácter dual, porque no solo interpreta textos mundanos, también crea textos que están afectados por condiciones sociohistóricas concretas: 
"en lugar de estar definida por un pasado silente, que le ordena hablar en el presente, la crítica, no menos que cualquier otro texto, es el presente en su proceso de articulación, en su batalla por la definición" (ibíd., 2004: 75).

¿Pero quiere esto decir que el Booktube puede ser una forma de crítica de nuestros tiempos? Siguiendo a autores clásicos a este respecto como Peter Hamm (I97I) o S.M. Schreiber (197I), el crítico tiene una función social: discernir entre la profusa producción editorial lo verdaderamente válido. Aunque Hamm recela de la figura del crítico debido a los intereses comerciales ante los que se puede doblegar, no deja de restarle validez teniendo en cuenta que, si siempre fuera así, los críticos "se verían obligados a informar casi exclusivamente acerca de las novelas policíacas, de ciencia-ficción y literatura trivial en general” (I971: 27). A pesar de las décadas transcurridas desde que el crítico alemán escribiera estas palabras, es curioso que esta sospecha siga vertiéndose sobre los booktubers. Es cierto que muchos de estos no consideran que lo que llevan a cabo en sus canales sea verdadera crítica, pero sí son conscientes de que realizan recomendaciones a las que sus seguidores les otorgan cierto crédito. O bien, y simplemente, que en su elección de unos títulos en detrimento de otros, están estableciendo un canon. La cuestión es si el tipo de comentarios que efectúan son legítimos desde un punto de vista literario... pero ¿quién asegura esa legitimidad? Si tradicionalmente la academia ha ostentado esta responsabilidad como institución inapelable, como ya hemos comentado, en esta ocasión su opinión es fuertemente contrarrestada por la de los booktubers, convertidos en autoridad para un importante grupo de lectores.

Principalmente el fenómeno Booktube es contemplado como un fenómeno fan, tanto por la labor de los creadores de los videos (supuestamente no actúan bajo ninguna relación contractual) como por la interacción entre los seguidores de las cuentas, algo que provoca una consideración negativa por parte de la cultura hegemónica. La cuestión es que ya la propia noción de fan es denostada tradicionalmente como resultado de "una proyección de las preocupaciones sobre la violación de las jerarquías culturales dominantes" (Jenkins, 20IO: 30). Entre otros productos típicos del fenómeno fandom, como el fanfiction, el hecho de que los booktubers se ocupen del comentario de formas de literatura no canónicas desplaza este tipo de manifestaciones a un lugar marginal dentro del sistema cultural, incapaz de asumir la labor que estos llevan a cabo sin fricciones por no reflejar los supuestos grandes títulos de la literatura.

Otra cuestión sería ver si el Booktube es una forma de crítica literaria. Kevin Perromat (2OI4) sintetiza en tres las líneas de discusión clásicas en torno a la labor de la crítica. La primera hace mención a su estatus discursivo. Según esto, los booktubers no elaboran su discurso desde lo literario o lo académico, ni siquiera como forma periodística especializada, estaríamos ante apasionados amateur que emprenden la labor de reflejar en sus canales el amor que sienten hacia la literatura, lo que desemboca en una forma de crítica impresionista (Wahnón, r99ı: 65-66). Estaríamos ante una forma laxa de crítica, pero que evidentemente tiene un efecto prescriptivo para sus seguidores. La segunda línea de discusión versa sobre si realmente orienta los buenos gustos literarios, 
configurando un canon futuro de calidad. Sobre el buen gusto, Pierre Bourdieu (I99I) argumentó que era fruto del consenso entre ciertos elementos del sistema que ocupan una posición hegemónica, y que, en consecuencia, instauraba un modelo concreto marcado por el sentido de distinción. Pero, como hemos visto, la selección de títulos efectuada por los booktubers sí promociona unos libros en detrimento de otros, lo que genera en consecuencia un canon, aun periférico, pero que sí puede participar activamente en los procesos de canonización. La última cuestión a la que hace mención Perromat es acerca del punto de vista ideológico -o comercial- desde el que se efectúa la crítica. Teniendo en cuenta este aspecto, la libertad con la que actúan los creadores de estas cuentas de YouTube-aunque luego sean captados por la industria editorial- hace que estos se granjeen la simpatía de los usuarios por su espontaneidad y sinceridad aparente en sus comentarios, fruto de una pasión que es compartida por sus seguidores.

La tipología de los programas de Booktube es variada. Encontramos algunos que fomentan la participación y la interactividad de los usuarios, como sería el caso de los Book Tags, en el que se hacen preguntas sencillas sobre libros, o los Book Challenges, donde las preguntas son más complejas e implican el conocimiento de la lectura tratada en el video. Pero si hay algunos que resultan sumamente curiosos son el Bookshelf tour, donde se realiza un paseo por la biblioteca del booktuber comentando sus libros y los criterios de organización en los estantes; el Unboxing, formato común en el mundo youtuber, en este caso abriendo paquetes de libros comprados o regalados por otros booktubers o editoriales; y los Book Hauls, donde se muestran las últimas adquisiciones. Resulta llamativo que el fenómeno Booktube, nacido en la red social YouTube, centre su atención sobre la literatura convencional en formato impreso, olvidándose de la literatura digital en todas sus formas. Aunque pueda parecer paradójico, supone una manifestación clara de la cibercultura, en tanto que se constituye en un ejemplo de la tensión entre la tecnofilia y la tecnofobia (Sánchez-Mesa, 2004: I5) fruto de un doble fetichismo: por las nuevas tecnologías y, por otro lado, por los medios tradicionales analógicos, es decir, el libro impreso. Pero lo más interesante es que de esta colisión se genera un producto tan genuino y heterodoxo como el Booktube.

Los booktubers también comentan libros que desean leer, el To be Read, o el Wish List, libros que además no tienen en ese momento y solicitan de algún modo. Esto les separa de la crítica convencional, que solo tratan obras una vez que han sido leídas. Pero es en la modalidad Wrap up, donde se lleva a cabo un rápido recorrido por las lecturas acometidas recientemente, donde podemos encontrar formas de crítica literaria de una manera más sistematizada. Con un ritmo rápido propio de la narrativa youtube, alternado con grafismo, sonido e imágenes, se va dando paso a las tramas, personajes y valoraciones sobre libros que a su vez van mostrándose a cámara. Los comentarios son asistemáticos, sin acogerse a ninguna corriente crítica concreta, y sin utilizar tecnicismos que puedan disuadir a la audiencia. La búsqueda de empatía con su público, de entre i2 y 24 años mayoritariamente, les lleva asimismo a usar expresiones coloquiales con abundancia de jerga juvenil. 


\section{Conclusiones}

Dado que la cuestión es tratar de ver si realmente estamos ante una forma de crítica stricto senso, y en qué tipología se podría incardinar, si nos atenemos a la serie de formas que puede adoptar la crítica literaria según Edward W. Said, el fenómeno Booktube no encajaría en ninguna de ellas. Si acaso, se asociaría a la forma bajo la que se agrupan las reseñas de los libros y el periodismo literario (2004: II), aunque el investigador lo vincula al ámbito profesional esencialmente, y no olvidemos que el fenómeno Booktube tiene un evidente tono amateur que marca incluso su estética, lo que no hace del todo aplicable esta categorización sobre esta forma de epitextualidad literaria.

A la hora de seleccionar un conjunto de obras que deben formar parte del canon, es curioso que, a pesar de aparecer en los videos obras del canon central con relativa frecuencia (los clásicos, principalmente), se centren en obras del canon periférico, como puede ser la literatura juvenil o la de ciencia ficción. Esto demuestra cómo dentro del polisistema cultural pueden coexistir diferentes estratos de canonización, donde el estrato central se puede ver amenazado ante la presión de una serie de elementos no canonizados que están en continua tensión con el estrato central, con el que acaban conviviendo o, incluso, sustituyendo (Even-Zohar, 2OI7: 9).

Lo que está claro es que, entendido el fenómeno Booktube como crítica digital, "Lo que ahora era crítica inmediata, ahora lo es más, pero es también crítica universal, porque universal es el medio en el que aparece" (Pulido, 2OI2: 9). Es decir, la accesibilidad que proporciona internet a los contenidos alojados en YouTube proporciona una gran distribución a la que los medios convencionales no podían acceder. Y además usando un formato totalmente asequible para todos los públicos, favoreciendo el engagement con un público juvenil ávido de nuevas actualizaciones en el canal y que se siente interpelado por la estética youtuber, favoreciendo de este modo la aparición de nuevos lectores.

No podemos obviar que dentro de la cultura de la convergencia en la que vivimos actualmente, y como nos dice Henry Jenkins (2008: 29), nos encontramos ante un nuevo paradigma sociocomunicativo donde los consumidores correspondientes al viejo modelo, que eran pasivos en torno al fenómeno literario, han sido desplazados por una nueva tipología. Ahora los lectores participan activamente, ya sea de forma previa, durante o después de la lectura, aportando para ello comentarios, valoraciones o críticas que vienen a modificar el proceso comunicativo literario tradicional. El fenómeno Booktube se configura en una buena muestra de todo esto, donde al lector se le ofrecen nuevas formas de aproximarse al texto, en este caso mediado por los canales audiovisuales de booktubers que, además, se constituyen en una autoridad a la hora de sancionar las obras que responden a sus criterios estéticos. Frente a la hegemonía del poder tradicional sobre la cultura, con criterios homogéneos que han sido reproducidos de forma acrítica y mecánica durante generaciones en casos, este tipo de prácticas se configuran en un relato polifónico que viene a democratizar el acceso a la literatura. 
Es por ello necesario que consideremos oportuna una revisión de las posibilidades del fenómeno Booktube para el fomento a la lectura, especialmente en ámbitos como el universitario, no perdiendo nunca de vista que el "triunfo de la interactividad y de la interacción en tiempo real, de la posibilidad de simultanear discursos plurales y multiculturales [...] es la consecuencia de una forma de comunicación donde impera el protagonismo del lector, receptor, oyente, internauta” (Morales Sánchez, 2OI6: 20). 


\section{Bibliografía}

-Alberro, A. (20II). Crítica, dialéctica y utopía. En A. Molina Climent (Dir.). Los lugares de la crítica (pp. 47-58). Pamplona: Universidad Pública de Navarra.

- Aparici, R. y García Marín, D. (2018). Prosumidores y emirecs: Análisis de dos teorías enfrentadas. Comunicar, 55, 7I-79. Obtenido el Io de febrero de 2019 desde https://doi. org/IO.39I6/C55-20I8-O7

- Baetens, J. y Sánchez-Mesa, D. (20I5). Literature at the Expanded Field: Intermediality at the Crossroads of Literary Theory and Comparative Literature. Interfaces, 36. Obtenido el I8 de febrero de 2019 desde preo.u-bourgogne.fr/interfaces/index.php?id=245

- Bourdieu, P. (I99I). La distinción: criterios y bases sociales del gusto. Madrid: Taurus.

- Cloutier, J. (1973). La communication audio-scripto-visuelle à l'heure des self média. Montreal: Les Presses de l’Université.

- Even-Zohar, I. (I999). Factores y dependencias en la cultura. Una revisión de la Teoría de los Polisistemas. En M. Iglesias Santos (Comp.). Teoría de los Polisistemas (pp. 23-52). Madrid: Arco Libros.

- Even-Zohar, I. (20I7). Polisistemas de Cultura. Tel Aviv: Universidad de Tel Aviv. Obtenido el 5 de diciembre de 2018 desde https://www.tau.ac.il/ itamarez/works/papers/trabajos/index.html

- Gaudreault, A. y Jost, F. (2OOI). Elrelato cinematográfico: ciencia y narratología. Barcelona: Paidós.

- Genette, G. (2OOI). Umbrales. México D.F.: Siglo XXI.

- Hamm, P. (i97I). El gran crítico. En P. Hamm (Ed.). Crítica de la crítica: crítica, de quién, para quién cómo (pp. 23-45). Barcelona: Barral Editores.

- Jenkins, H. (2008). Convergence Culture. La cultura de la convergencia de los medios de comunicación. Barcelona: Paidós.

- Jenkins, H.(20IO). Piratas de textos: fans, cultura participativa y televisión. Barcelona: Paidós.

- Kermode, F. (1998). El control institucional de la interpretación. En E. Sullá (Comp.). El canon literario (pp. 9I-II2). Madrid: Arco Libros. 
- Landow, G. (Comp.) (1997). Teoría del hipertexto. Barcelona: Paidós.

- Lluch, G., Tabernero-Sala, R. y Calvo-Valios, V. (2OI5). Epitextos virtuales públicos como herramientas para la difusión del libro. El profesional de la información, 24(6), 797-804.

- Márquez, I. y Ardévol, E. (2OI2). Hegemonía y contrahegemonía en el fenómeno youtuber. Desactos, 20I2, 34-49.

- Morales Sánchez, M. I. (2OI6). Estrategias de formación lectora en la universidad: la literatura como ámbito transversal para un aprendizaje integrado de la cultura. Álabe, r3. Obtenido el I5 de enero de 2oI9 desde DOI: IO.I5645/Alabe2OI6.I3.2

- Perromat, K. (2OI4). El apocalipsis que nunca llega. Crisis y representaciones de la crítica literaria actual. Líneas, Revue Interdisciplinaire d'Études Hispaniques, (I). Obtenido el to de febrero de 20I9 desde https:// revues.univ-pau.fr/lineas/ı297

- Pulido, G. (2012). La crítica literaria española frente a los nuevos medios y el cambio. Revista caracteres. Estudios culturales y críticos de la esfera digital, 2, 29-38.

- Rovira Collado, J. (2OI6). Del blog de LIJ 2.o al booktuber en la promoción del hábito lector. Revista de Estudios Socioeducativos, 4, 37-5 ${ }^{\mathrm{I}}$.

- Rovira Collado, J. (20I7). Booktrailer y Booktuber como herramientas LIJ 2 .o para el desarrollo del hábito lector. Investigaciones sobre lectura, 7, 55-72.

- Said, E. W. (2004). El mundo, el texto y el crítico. Barcelona: Debate.

- Sánchez-Mesa, D. (Comp.) (2004). Literatura y Cibercultura. Madrid: Arco Libros.

- Schreiber, S. M. (197I). Introducción a la crítica literaria. Barcelona: Labor.

- Sullá, E. (1998). El debate sobre el canon literario. En E. Sullá (Comp.). El canon literario (pp. II-34). Madrid: Arco Libros.

- Toffler, A. (1994). La tercera ola. Barcelona: Plaza \& Janés.

- Wahnón, S. (I99I). Introducción a la historia de las teorías literarias. Granada: Universidad de Granada. 